\title{
The Roles of Toll-Like Receptors in Atherosclerosis
}

\author{
Clett Erridge
}

Department of Cardiovascular Sciences, Leicester University, Glenfield General Hospital, Leicester, UK

\section{Key Words}

Toll-like receptors - Atherosclerosis · Endotoxin ·

Pathogen-associated molecular patterns .

Innate immunity $\cdot$ Foam cell formation

\begin{abstract}
Atherosclerosis is a chronic inflammatory disease of the arteries that is characterised by the activation of endothelial cells, the recruitment of monocytes into the vessel wall and the differentiation of recruited macrophages into cholesterol-laden foam cells. Recent evidence from a variety of experimental approaches has indicated that Toll-like receptors (TLRs), which serve to initiate inflammatory signalling in response to the detection of molecules associated with microbial infection or tissue damage, play key roles in the development of atherosclerosis. This review summarises the recent evidence implicating TLR-dependent signalling in the activation of vascular cells during atherogenesis, and the mechanisms by which TLR-signalling may promote the dysregulation of macrophage cholesterol metabolism that is a prerequisite for the formation of foam cells and lesion progression in vivo. Particular attention is paid to the recent studies aimed at identifying potential ligands of the TLRs that may be relevant to atherogenesis, and the diverse mechanisms by which vascular tissues may become exposed to ligands of the TLRs.

Copyright $\odot 2009$ S. Karger AG, Basel
\end{abstract}

\section{Introduction}

Atherosclerosis is a chronic degenerative disease of the arteries that represents the root cause of the majority of cardiovascular diseases (CVDs) and their complications, including conditions such as coronary artery disease, myocardial infarction and stroke. According to World Health Organization estimates, CVDs were responsible for approximately $30 \%$ of deaths globally in 2003 , reflecting both a higher incidence of CVDs in developed nations and an increasing prevalence of CVDs in many developing ones [1]. Atherosclerosis is also a leading cause of disability, as CVDs have been found to be responsible for almost a quarter of the disability-adjusted life years lost in the European Union [2].

The precise aetiology of atherosclerosis remains to be clearly elucidated, although the key stages that define the development of the atherosclerotic lesion are now well established (as summarised in fig. 1). One of the earliest of these events is the activation of endothelial cells to express adhesion molecules and chemokines. This leads to the recruitment of circulating monocytes and, to a lesser extent, other leucocytes such as $\mathrm{T}$ cells into the subendothelial space (intima) of the artery wall. Recruited monocytes mature into macrophages which may then absorb excessive quantities of cholesterol and other lipids to become lipid-laden 'foam cells', so called on the basis of their histological appearance. This forms the earliest detectable form of the lesion, termed the fatty streak, which

Dr. Clett Erridge

Department of Cardiovascular Sciences

Leicester University, Glenfield General Hospital

Leicester LE3 9QP (UK)

Tel. +44 116256 3048, Fax +44 116287 5792, E-Mail ce55@leicester.ac.uk 
may appear in the arteries of subjects from as early as their teenage years. At this stage, the lesion is relatively dynamic, and may either regress through macrophage emigration and repair, or grow to become more complex, in a manner dependent on a variety of environmental and genetic factors [3].

As the lesion progresses, further recruitment of leucocytes, coupled with impaired emigration of recruited cells, leads to a net expansion in the number of foam cells in the artery wall. Initially, the vessel wall expands outwardly such that blood flow through the affected artery is not impaired. Over time, however, the lesion may enlarge inwardly to occlude blood flow and, as ageing foam cells die by necrosis, an acellular core of crystalline cholesterol and necrotic cell debris develops in the lesion. Driven by growth factors and cytokines, smooth muscle cells migrate into the plaque, depositing collagen to create a protective cap over an increasingly complex lesion. Plaques such as these may remain clinically silent for decades, although if the plaque becomes unstable, due to acute inflammatory events for example, plaque rupture may occur, leading to the formation of a thrombus which is the ultimate cause of vessel occlusion and emboli, heart attacks and strokes.

\section{Atherosclerosis Is an Inflammatory Disease}

Early efforts to understand the aetiology of atherosclerosis revolved mainly around large population studies that aimed to identify factors associated with increased risk of developing CVD. Such studies soon identified that the risk factors for the development of atherosclerosis are surprisingly diverse, including seemingly disparate modifiers such as age, smoking, insulin resistance, hypertension, elevated plasma cholesterol and diets rich in saturated fat. On the basis of this early evidence, it was assumed for many years that atherosclerosis is primarily a disease of dysregulated lipid metabolism.

However, a wealth of more recent evidence from 3 main investigative approaches has revealed that inflammatory processes also play a central role in the development of this disease. First, association studies have established that elevated circulating markers of systemic inflammatory status, such as C-reactive protein, interleukin (IL)-6, IL-8, tumour necrosis factor (TNF)- $\alpha$, and soluble vascular adhesion molecules, correlate well with cardiovascular risk in human subjects (as reviewed in [4]). Second, immunohistochemical studies have confirmed that inflammatory processes are active within the developing plaque, with the demonstration that inflammatory gene products, such as IL-6, intercellular adhesion molecule (ICAM)-1, vascular cell adhesion molecule (VCAM)-1, E-selectin and TNF- $\alpha$ are upregulated in human atheroma when compared to a control or adjacent healthy artery $[5,6]$.

However, perhaps the most compelling evidence that inflammation is a central mediator of atherosclerosis, rather than merely an associated marker of the disease, has emerged from examination of animal models of atherosclerosis. Although mice are naturally resistant to the development of atheroma, mice engineered to be genetically deficient in apolipoprotein $\mathrm{E}\left(\mathrm{ApoE}^{-/-}\right)$, or the lowdensity lipoprotein receptor $\left(\mathrm{LDLR}^{-/-}\right)$, develop hypercholesterolaemia and aortic lesions that are similar to those observed in human subjects [7]. A crucial advantage of these models is that progression of the disease may be readily quantified in terms of the percentage of volume or surface area of artery affected by lesions. Animals of a similar genetic background harboring other genetic deletions may then be crossed with these models to allow a quantitative evaluation of the contribution of specific genes to the development of atheroma in these models. Such studies have revealed that deletion of almost any gene involved in pro-inflammatory signalling, including ICAM-1, VCAM-1, E-selectin, IL-18, chemokine CXC motif receptor-2, TNF- $\alpha$ and IL-1 $\beta$, leads to a significant reduction in atherosclerosis $[8,9]$. Accordingly, deletion of genes involved in the negative regulation of inflammation, such as IL-10, haem oxygenase- 1 and transforming growth factor- $\beta$, leads to a considerable acceleration in the development of atheroma $[10,11]$.

Taken together, these studies indicate that inflammatory signalling acts not merely as a marker associated with the development of the disease, but rather as a central mediator in its initiation and progression. Identifying the receptors and pathways responsible for stimulating inflammatory signalling in the diseased artery has therefore become a keenly pursued topic in recent years.

\section{Toll-Like Receptors Sense Damage or Pathogen-Associated Molecular Patterns}

The 10 human Toll-like receptors (TLRs) are a family of type-1 transmembrane receptors that play a critical role in host recognition of and defence against microbial infection. Each receptor serves to initiate inflammatory signalling in response to the detection of a corresponding pathogen-associated molecular pattern (PAMP). For example, TLR2, in conjunction with heterodimerisation 


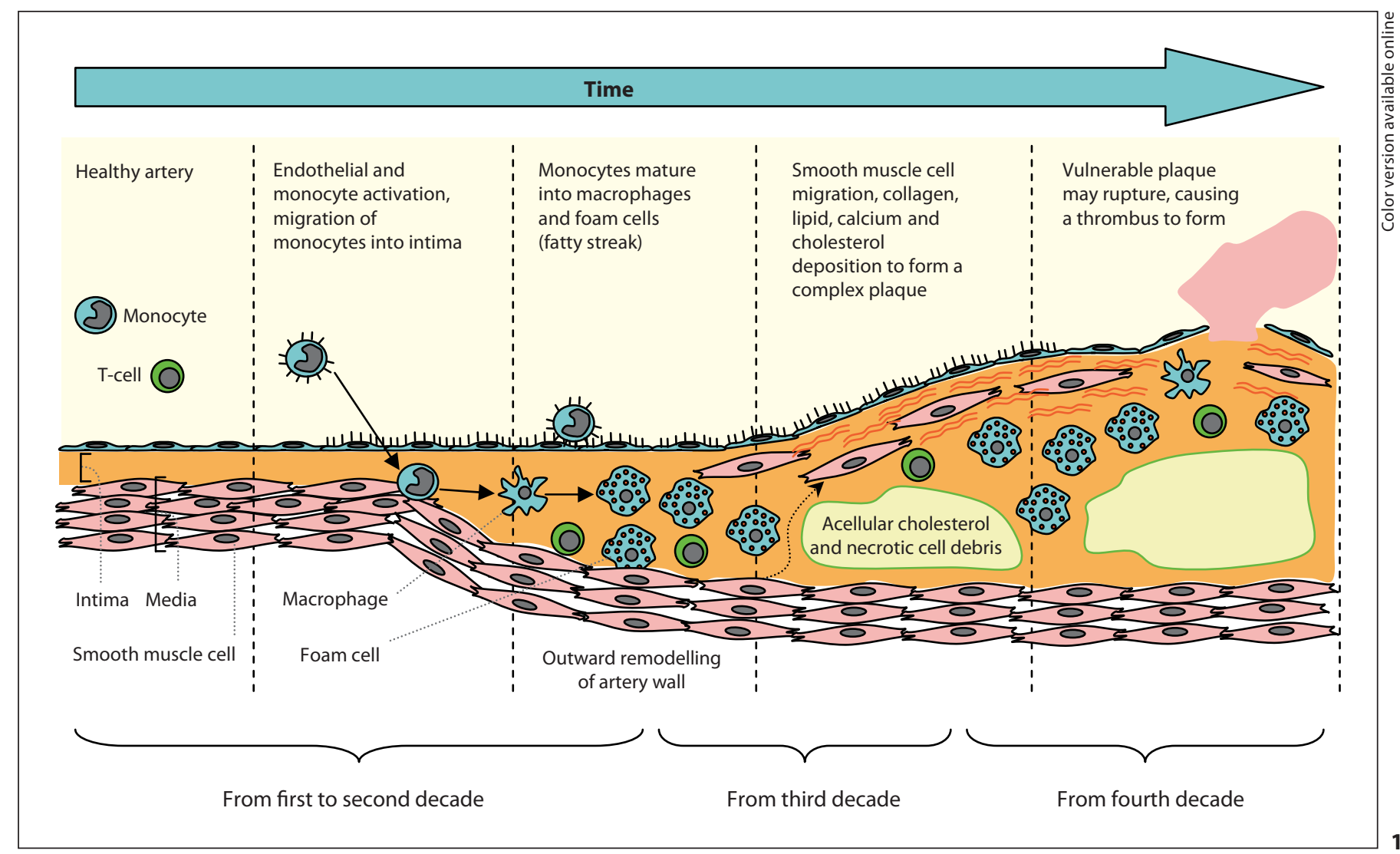

Fig. 1. Key stages in the development of atherosclerotic plaque. The first stage in atherogenesis is the activation of endothelial cells to express adhesion molecules and chemokines which promote the recruitment of circulating monocytes and, to a lesser extent, other leukocytes such as T cells, into the subendothelial space (intima) of the artery wall. Recruited monocytes differentiate into macrophages, which then absorb lipid and cholesterol to become foam cells that are less able to emigrate from the plaque. At this stage the lesion, which is termed the fatty streak, does not protrude into the vessel wall. Over many years, further foam cells may accumulate to enlarge the plaque and occlude the vessel lumen. These cells may ultimately die by necrosis, leaving a 'necrotic core' of crystalline cholesterol and cell debris. Smooth muscle cells proliferate and migrate into the region, laying down a protective cap over the lesion. Lesions may remain stable and clinically silent for decades, until further inflammatory events - particularly those involving macrophage expression of matrix metalloproteinases - may trigger plaque rupture and the formation of a thrombus that is the ultimate cause of acute myocardial infarction and stroke. Approximate mean time of onset of each stage of plaque progression is indicated below the figure.

Fig. 2. Effect of Toll-like receptor signalling on macrophage cholesterol metabolism. Stimulation of TLR3 or TLR4 leads to TRIFdependent activation of IRF3, which inhibits transcription of liver X receptor-dependent genes, many of which (e.g. ATP-binding cassette transporter A1, PLTP, apoE and ABCG-1) are critically involved in the efflux of cholesterol from macrophages. It is not yet clear how TLR2 stimulation promotes foam cell formation, as IRF3 is not activated by this receptor, although activation of NF-

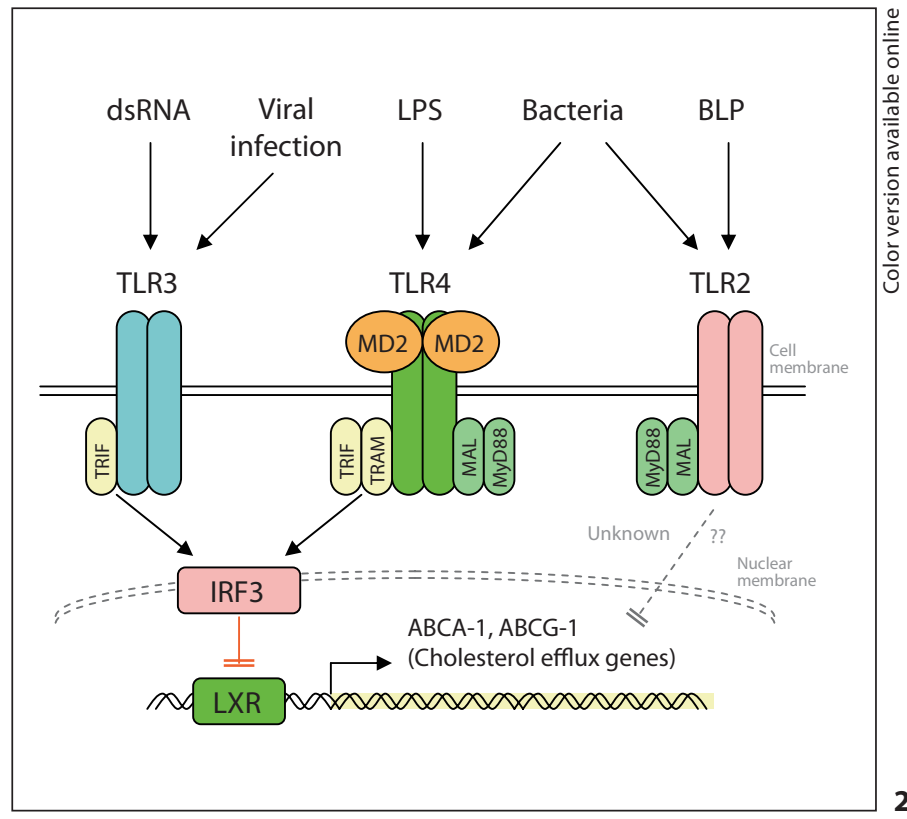

$\kappa \mathrm{B}$ and down-regulation of SR-B1 has been proposed to play a role. TRIF = TIR-domain-containing adapter-inducing interferon- $\beta$; TRAM $=$ TRIF-related adaptor molecule; MAL = MyD88adapter-like; MyD88 = myeloid differentiation factor 88; IRF3 = interferon regulatory factor 3 ; LXR = liver X receptor; $\mathrm{ABCA}-1=$ ATP-binding cassette transporter A1. 
partners TLR6 or TLR1, recognises di-acyl or tri-acyl bacterial lipopeptides, respectively. TLR3 recognises double-stranded RNA motifs, while TLR7 and TLR8 appear to recognise single-stranded RNA signatures, both of which are typically associated with viral infections. TLR4, with the assistance of MD2, recognises enterobacterial lipopolysaccharide (LPS), while TLR5 and TLR9 recognise flagellin and unmethylated $\mathrm{CpG}$ motifs that are common in bacterial DNA, respectively (reviewed in [12]). In addition to microbial motifs, emerging evidence suggests that TLRs may also serve to detect endogenous products of host tissue damage [13].

In all cases, the physical engagement of a PAMP with its respective TLR, directly or via an adaptor protein (such as MD2), is thought to lead to receptor dimerisation and the recruitment of intracellular signalling adaptor proteins that stimulate inflammatory signalling. Generally speaking, signalling downstream from all TLRs (other than TLR3) involves myeloid-differentiation-factor-88 (MyD88)-dependent activation of p38, Erk and Jnk mitogen-activated protein kinases, degradation of $І \kappa B \alpha$ and the activation of nuclear factor (NF)- $\kappa \mathrm{B}$-dependent signalling, while TLR 3 and TLR4 also stimulate interferon regulatory factor-3-dependent signalling via recruitment of the alternative signalling adaptor TRIF (TIR-domaincontaining adapter-inducing interferon- $\beta$; as reviewed recently and comprehensively in [14]). In most cell types, the stimulation of TLR-dependent signalling results in a rapid upregulation of expression of inflammatory genes, such as endothelial adhesion molecules, chemokines and inflammatory cytokines.

\section{Expression of Toll-Like Receptors in the Vasculature}

While previously thought to be expressed mainly by cells of the immune system, it has emerged that most cell types express at least 1 of the 10 human TLRs. Arteries in particular have been found to express a surprisingly extensive repertoire of TLRs. For example, TLRs 2, 3, 4, 5 and 9 were reported to be expressed by arterial endothelial cells $[15,16]$, while arterial smooth muscle cells express mRNA for TLRs 3, 4, 5 and $9[16,17]$. Macrophages, the principal cell type within atheroma, express all of the TLRs and are responsive to all TLR ligands [16]. Functional studies have confirmed that vascular cells are responsive to diverse TLR ligands. For example, smooth muscle cells are responsive to ligands of TLR3, TLR4 and TLR9, whereas venous endothelial cells are responsive to ligands of TLRs 3, 4, 5 and 9 and coronary artery endothelial cells
Table 1. Summary of murine genetic models of TLR-dependent atherosclerosis

\begin{tabular}{lllll}
\hline $\begin{array}{l}\text { Gene } \\
\text { knocked out }\end{array}$ & $\begin{array}{l}\text { Genetic } \\
\text { background }\end{array}$ & Diet and time & $\begin{array}{l}\text { Reduction in } \\
\text { lesion area, \% }\end{array}$ & $\begin{array}{l}\text { Refer- } \\
\text { ence }\end{array}$ \\
\hline MyD88 $^{-/-}$ & ApoE $^{-/-}$ & HFD, 2 months & $40-65$ & 19 \\
MyD88 $^{-/}$ & ApoE $^{-/}$ & HFD, 6 months & 57 & 20 \\
TLR2 $^{-/}$ & LDLR $^{-/}$ & HFD, 14 weeks & 50 & 21 \\
TLR2 $^{-/}$ & ApoE $^{-/}$ & chow, 7 months & $65-70$ & 22 \\
TLR2 $^{-/}$ & ApoE $^{+/-}$ & chow, 6 months & 100 & 23 \\
TLR2 $^{-/-}$ & ApoE $^{-/-}$ & HFD, 6 months & 100 & 23 \\
TLR4 $^{-/}$ & ApoE & HFD, 6 months & 24 & 20 \\
\hline
\end{tabular}

Percentage reduction in lesion area as calculated by en face staining of aortas from TLR- or MyD88-deficient animals compared to MyD88- or TLR-competent control animals is shown. Where 2 figures are shown in 1 column, the first relates to the reduction in female mice, the second to male mice. HFD = High-fat diet; chow $=$ normal mouse chow.

are additionally (and uniquely among non-myeloid vascular cells) responsive to TLR2 ligands $[15,16,18]$.

It has been suggested that the latter observation may help to explain the fact that while veins are typically resistant to the development of atherosclerosis, arteries, and in particular the coronary artery, are susceptibile to the disease [18]. Interestingly, it has also been reported that endothelial TLR2 expression is upregulated in response to disturbed blood flow conditions [15]. This has led to the proposal that flow-regulated TLR2 expression may also contribute to the regiospecificity of atherosclerosis, as the regions of arteries that are at greater risk of plaque formation are typically observed in regions of disturbed blood flow, such as bifurcations or inner curvatures of the arteries [15].

\section{Evidence for a Role for TLRs in Atherosclerosis}

Recent genetic studies in $\mathrm{ApoE}^{-/-}$and $\mathrm{LDLR}^{-/-}$mice have revealed a central role for TLR signalling in the development of atherosclerosis. Deletion of the shared TLR signalling adaptor MyD88 leads to a reduction in plaque burden of around $60 \%[19,20]$. Likewise, specific deletion of either TLR2 or TLR4 also leads to a significant reduction in atherosclerosis burden (as summarised in table 1) [20-23]. Of particular interest, Madan et al. have recently reported that while lesions readily form in the aortas of TLR competent heterozygous $\mathrm{ApoE}^{+/-}$mice, no lesions at all were detectable in TLR2 deficient mice, even after 6 
months on a high fat diet or with recurrent atherogenic pathogen challenge [23]. The more central role played by TLR2 in this model may relate to the fact that $\mathrm{ApoE}^{+/-}$ mice develop a less severe hypercholesterolaemia than $\mathrm{ApoE}^{-/-}$mice, thereby revealing more of the cholesterolindependent pathways of atherogenesis. Beyond genetic studies, however, further evidence for the atherogenic nature of TLR signalling has emerged with the observations that recurrent injection of mice with low doses of the TLR4 ligand LPS [24, 25], or with TLR2 ligands, such as synthetic bacterial lipopeptides, leads to a significant acceleration of atherogenesis $[21,23]$.

Evidence suggests that TLRs may also play a role in human atherogenesis. TLRs 1, 2, 4, 5 and 6 have been reported to be highly upregulated in human atheroma when compared to healthy control artery, and NF- $\mathrm{\kappa B}$ activation has been noted to co-localise with cells within plaques that express TLR2 or TLR4 [26]. Functional studies have also confirmed that excised and cultured human carotid plaques secrete TNF- $\alpha$ and IFN- $\gamma$ in response to treatment with the TLR4 and TLR9 ligands LPS and CPG DNA, respectively [27].

\section{Regulation of Macrophage Cholesterol Metabolism by TLR Signalling}

The differentiation of macrophages into lipid-laden foam cells is a critical step in the development of atheroma. The longest-held hypothesis for the mechanism of foam cell formation in atherogenesis proposes that LDL particles may become oxidised within the vessel wall (forming so-called OxLDL), and that these modified particles may be subsequently taken up by macrophage scavenger receptors. However, certain observations are difficult to reconcile with this notion, such as the failure of antioxidant therapies to improve cardiovascular outcome in human trials [28], and the fact that genetic deletion of scavenger receptors CD36 or SR-A does not inhibit foam cell formation in $\mathrm{ApoE}^{-/-}$mice [29].

In light of these observations, alternative potential mechanisms for the formation of foam cells during atherogenesis have been sought, and bacteria and their products have emerged as candidate mediators. For example, it has been shown that treatment of macrophages with LPS in the presence of native (unoxidised) LDL leads to rapid uptake of lipid and differentiation of macrophages into foam cells in a manner that cannot be reversed by antioxidants [30]. Likewise, treatment of human and murine macrophages with intact bacteria, such as Chlamyd- ia pneumoniae or Porphyromonas gingivalis, was shown to promote foam cell formation independently of bacterial viability, lipoprotein oxidation or competitive inhibition of scavenger receptors [31,32].

Several lines of evidence suggest that the mechanism underlying bacteria-induced foam cell formation involves PAMP-mediated stimulation of TLR-dependent signalling. For example, it was shown that the bioactive component of $C$. pneumoniae that promotes foam cell formation is likely to be LPS, as this factor was found to be heat-stable and could be inhibited by treatment with periodate or lipid-X, an antagonist of LPS signalling [33]. Furthermore, a number of studies confirmed that stimulation of macrophages with purified, specific ligands of TLR2 [34], TLR4 [30, 32, 33] or TLR9 [35] also promoted foam cell formation.

Two main proposals have been put forward to explain how TLR-dependent signalling could promote macrophage cholesterol accumulation (fig. 2). First, it was shown that TLR3- or TLR4-dependent induction of IRF3 signalling potently inhibits liver X receptor-dependent expression of genes such as ATP-binding cassette A-1 (ABCA-1) and ABCG-1, that are involved in the efflux of cholesterol from macrophages [36]. However, this mechanism cannot explain TLR2- or TLR9-dependent foam cell formation, as IRF3 is not activated by these TLRs. Alternatively, it has been suggested that the activation of NF- $\mathrm{KB}$, a transcription factor induced by all of the TLRs, could also lead to downregulation of cholesterol efflux genes, such as ABCA1-binding cassette transporter A1 and SR-B1, leading to a net accumulation of cellular cholesterol-ester [37].

The likely physiological purpose of this link between TLR signalling and cholesterol uptake is currently debated. Interestingly, it has been shown that foam cells are inherently more resistant to infection with intracellular bacteria than normal macrophages, and that the growth of such bacteria is significantly inhibited in foam cells [38]. Thus, it is possible that the observed crosstalk between TLR stimulation and lipid accumulation may reflect an adaptive response that has evolved to limit the spread of macrophage-borne pathogens before and during reproductive age, when the negative consequences of atherosclerosis are unlikely to apply a selective pressure.

\section{Potential Ligands of TLRs in Atherosclerosis}

The emerging understanding that TLR signalling contributes to atherosclerosis has promoted the search for candidate ligands that may be responsible for stimulating 
TLRs in the vascular wall. Numerous proposals have been put forward for such candidates, which typically fall into 1 of 3 categories: (1) unoxidised endogenously produced molecules that play immune regulatory roles; (2) oxidatively modified host lipids or lipoproteins, and (3) exposure of vessels to the established (i.e. microbial) ligands of the TLRs.

\section{Candidate Endogenous TLR Ligands}

Since the development of sensitive assays for the detection of TLR-stimulating molecules, dozens of compounds of diverse origin have been reported to stimulate signalling via TLRs. Several of these are endogenous molecules of host cell origin that are proposed to mediate their immune regulatory effects via stimulation of specific TLRs. Examples of such proposals include the TLR2- and TLR4stimulatory capacity of heat shock proteins, high mobility group box 1 (HMGB-1), fibronectin extra domain-A, hyaluronan fragments, biglycan and even saturated fatty acids (as reviewed in [13]).

However, it should be noted that many researchers feel that these reports should be interpreted with caution, as the established microbial ligands of TLR2 and TLR4, namely BLP and LPS, are common contaminants of lipid and recombinant protein preparations [39]. This has led to several high-profile mis-identifications of novel TLR agonists, such as C-reactive protein and heat shock proteins, the pro-inflammatory properties of which were both shown subsequently to be due to endotoxin contamination of the reagents used in these studies $[40,41]$. Nevertheless, it is interesting to note that of the endogenous TLR-ligand proposals so far put forward, no evidence to the contrary for high mobility group box 1 and fibronectin-EDA being TLR ligands has yet been published, and that genetic deficiency in fibronectin-EDA leads to reduced atherosclerosis in $\mathrm{ApoE}^{-/}$mice [42], while expression of high mobility group box 1 appears to be upregulated in human atheroma [43].

\section{Oxidatively Modified Lipids and Lipoproteins}

The proposal that oxidation of LDL may be the principle catalyst promoting the formation of foam cells has led many researchers to examine the possibility that $\mathrm{Ox}$ LDL may also promote inflammatory signalling in the vessel wall. Thus, considerable interest was generated by early reports that minimally modified LDL (mmLDL) and oxidised phospholipids (OxPLs) may stimulate TLR4-dependent signalling $[44,45]$. However, we showed recently that neither oxidised phospholipids nor oxysterols or oxidised LDL are capable of stimulating TLR2- or TLR4-dependent signalling in diverse human and murine cell types, and that an artefact of the cell-line chosen for the earlier studies explains the apparent TLR4 response to OxPLs $[46,47]$. Instead, we and others have shown that OxLDL and OxPLs are potent inhibitors of TLR signalling $[46,48-50]$. Accordingly, it is worth noting that while many studies have established that TLR stimulation can result in activation of NF- $\kappa \mathrm{B}$, and expression of ICAM-1, VCAM-1, E-selectin, TNF- $\alpha$ and IL$1 \beta$, all of which are upregulated in atheroma as discussed above, these specific inflammatory gene products are not induced by OxPLs or OxLDL [46, 47, 49, 51]. Observations such as these have led to a renewed effort to identify alternative sources of TLR-stimulants within the diseased artery wall.

\section{Evidence that Atheroma May Be Exposed to Bacteria and Their PAMPs}

The last 20 years or so has seen a revival of interest in the notion that atheromatous lesions may be exposed directly to bacterial or viral pathogens during their development. This revival has been promoted by the frequent demonstration that cardiovascular risk appears to correlate well with current or prior infection with organisms such as C. pneumoniae, cytomegalovirus, Helicobacter pylori, $P$. gingivalis and herpes simplex virus, in large association studies $[52,53]$. Interestingly, and in contrast to the traditional concept of Koch's postulates, it appears that no single organism is alone responsible for increased cardiovascular risk, as several studies have shown that it is the overall, cumulative 'infectious burden', as measured by history and seropositivity to many different pathogens, that appears to represent the more reliable risk factor for the disease $[54,55]$. Indeed, animal models have confirmed that experimental infection with organisms as diverse as C. pneumoniae, P. gingivalis, Pseudomonas aeruginosa and herpes virus each promotes atherosclerosis, in some cases even in the absence of elevated plasma cholesterol $[9,56,57]$.

Bacterial signatures are also frequently detected in human atheroma. Molecular and immunohistochemical studies have demonstrated the presence of the PAMPs LPS, peptidoglycan and bacterial DNA in a high proportion of lesions [58-60]. Interestingly, bacterial DNA can 
remain preserved in tissues for many years after all other traces of infection are cleared, and is considered by many researchers to provide a historical record of a tissue's prior exposure to bacterial infection [61]. On the basis of this principle, we and other groups have applied molecular cloning techniques to establish the diversity of conserved bacterial 16S gene DNA signatures in human atheroma. Remarkably, signatures from a diverse variety of bacteria, ranging from common pathogens to commensal and environmental organisms, are present in human atheromatous tissue, but crucially are all but absent from healthy arteries $[16,60,62,63]$. Based on such $16 S$ gene directed analyses of historical exposure to bacteria, it is likely that human atherosclerotic lesions may be commonly, if transiently, exposed directly to bacterial ligands of TLR2, TLR4, TLR5 and TLR9 [16].

Despite these findings, however, it should be noted that live organisms are only very rarely cultured from atheromatous tissue. Instead, it appears likely that bacterial antigens and DNA, rather than viable organisms, accumulate within atheroma [64], and that the PAMPs shed by and contained within bacteria may exert their atherogenic effects via stimulation of TLR-dependent signalling, independently of bacterial viability [21, 23-25]. Moreover, while experimental evidence has clearly shown that infectious agents can accelerate atherosclerosis, it has also been shown that they are not required for lesion formation, as gnotobiotic $\mathrm{ApoE}^{-/-}$mice raised in pathogen-free environments also develop atherosclerotic lesions [65].

\section{Direct Exposure of Vascular Cells to Circulating PAMPs}

Beyond infection and bacteraemia, it has emerged recently that vascular tissues may also be exposed directly to PAMPs in the circulation. PAMPs are shed and released by all growing and dividing bacteria, and the gastrointestinal tract in particular constitutes an enormous reservoir of biologically active soluble PAMPs such as BLP, LPS and flagellin. Although the gut barrier is highly effectively at preventing lumenal PAMPs from entering the circulation and thereby stimulating vascular TLRs, a small amount of endotoxin nevertheless translocates from the gut to reach detectable concentrations in the circulation of all healthy human subjects [54, 66, 67]. While it was previously assumed that the concentration of circulating endotoxin in health is too low to be of any pathophysiological relevance (it is generally in the pico- molar range), several large association studies have recently provided evidence that elevated basal circulating endotoxin concentrations correlate well with increased atherosclerosis risk in human subjects [67-69], adding valuable confirmation to the demonstration that LPS exposure, even at relatively modest levels, accelerates atherogenesis in animal models $[24,25]$.

Interestingly, it has also emerged recently that exposure to circulating PAMPs, such as endotoxin, could be modulated by a number of environmental and lifestyle factors that have been established as increasing cardiovascular risk. For example, we showed recently that a single high-fat meal is sufficient to increase the concentration of circulating endotoxin in human subjects by around 50\% post-prandially [70]. High-fat diet-induced endotoxaemia has also been shown to occur in mice, and this process appears to play a role in the induction of insulin resistance by high-fat diets [71]. Indeed, genetic deletion of the LPS receptor TLR4 was shown to reverse fatdiet-induced vascular inflammation [72] and insulin resistance [73]. Beyond fatty diets, it is interesting to note that 2 other atherogenic risk factors, namely obesity and insulin resistance, also correlate with elevated circulating endotoxin concentrations [66, 74, 75]. Thus, an emerging paradigm is that dietary and lifestyle choices may be previously unappreciated modulators of systemic exposure to endotoxin, and potentially other gut-derived PAMPs.

\section{Potential for Intervention}

Animal models of atherosclerosis suggest that inhibition of TLR-dependent signalling [19-23], or limitation of arterial exposure to PAMPs [21, 24, 25], may offer novel therapeutic approaches to the treatment or prevention of atherosclerosis. In terms of pharmacological intervention, it is interesting to note that members of the statin family, which are used clinically to reduce cholesterol levels and cardiovascular risk, inhibit LPS-induced TLR4signalling in vascular cells [76]. Drugs which competitively inhibit the binding of enterobacterial LPS to the TLR4/MD2 complex, such as lipid IVa (compound 406) and Eritoran, have been shown to efficiently inhibit TLR4-signalling in vitro and in vivo [77]. Thus, investigations of TLR inhibitors in animal models of atherosclerosis are warranted, although delivery of these mainly lipophilic and rapidly cleared agents will likely present some challenges.

In light of the evidence discussed earlier, and the disappointing results of several large clinical trials [78], it 
seems unlikely that antibiotic approaches that target a single organism will have a considerable impact on cardiovascular risk. Instead, attempts to reduce arterial exposure to PAMPs could hold more promise, and may include approaches such as reducing circulating endotoxin concentrations. Interestingly, treatment of insulin-resistant subjects with the insulin sensitising agent rosiglitazone reduced circulating LPS by approximately $35 \%$, via mechanisms that remain to be established [66]. If PAMPs derived from the gut flora contribute to systemic inflammatory tone, as is now being suggested by studies in animals [71,72], attempts to modify gut flora may also merit consideration. Indeed, treatment of mice with the prebiotic inulin has been shown to reduce lumenal concentrations of LPS [79], and result in an approximately $35 \%$ reduction in atherosclerosis in $\mathrm{ApoE}^{-/-}$mice [80]. Thus, the potential to modulate atherosclerosis via modulation of the gut-flora should not be ruled out.

\section{Summary}

Animal models of atherosclerosis have left little doubt that stimulation of TLR-dependent signalling contributes to the development of the disease. The key question that remains to be addressed in forthcoming studies is: what are the nature and origins of the agents that are responsible for stimulating TLR-dependent signalling in the diseased vessel wall? The identification of these agents will likely shed considerable new light on the aetiology of this disease, and enable the development of novel therapeutic approaches for the treatment or prevention of atherosclerosis which, all data indicate, is otherwise set to exert an ever increasing toll on human health.

\section{References}

1 Rosamond W, Flegal K, Friday G, Furie K, Go A, Greenlund K, Haase N, Ho M, Howard V, Kissela B, Kittner S, Lloyd-Jones D, McDermott M, Meigs J, Moy C, Nichol G, O'Donnell CJ, Roger V, Rumsfeld J, Sorlie P, Steinberger J, Thom T, Wasserthiel-Smoller S, Hong Y: Heart disease and stroke statistics 2007 update: a report from the American Heart Association Statistics Committee and Stroke Statistics Subcommittee. Circulation 2007;115:e69-e171.

2 Allender S, Scarborough P, Peto V, Rayner M, Leal J, Luengo-Fernandez R, Gray A: British Heart Foundation European Cardiovascular Disease Statistics, 2008 edition. www. heartstats.org/datapage. asp?id $=7683$

-3 Llodra J, Angeli V, Liu J, Trogan E, Fisher EA, Randolph GJ: Emigration of monocyte-derived cells from atherosclerotic lesions characterizes regressive, but not progressive, plaques. Proc Natl Acad Sci USA 2004;101: 11779-11784.

4 Ikonomidis I, Stamatelopoulos K, Lekakis J, Vamvakou GD, Kremastinos DT: Inflammatory and non-invasive vascular markers: the multimarker approach for risk stratification in coronary artery disease. Atherosclerosis 2008;199:3-11.

-5 Davies MJ, Gordon JL, Gearing AJ, Pigott R, Woolf N, Katz D, Kyriakopoulos A: The expression of adhesion molecules ICAM-1, VCAM-1, PECAM, and E-selectin in human atherosclerosis. J Pathol 1993;171:223-229.

-6 Barath P, Fishbein MC, Cao J, Berenson J, Helfant RH, Forrester JS: Detection and localisation of tumor necrosis factor in human atheroma. Am J Cardiol 1990;65:297-302.
7 Ohashi R, Mu H, Yao Q, Chen C: Cellular and molecular mechanisms of atherosclerosis with mouse models. Trends Cardiovasc Med 2004;14:187-190.

-8 Collins RG, Velji R, Guevara NV, Hicks MJ, Chan L, Beaudet AL: P-Selectin or intercellular adhesion molecule (ICAM)-1 deficiency substantially protects against atherosclerosis in apolipoprotein E-deficient mice. J Exp Med 2000;191:189-194.

-9 Chi H, Messas E, Levine RA, Graves DT, Amar S: Interleukin-1 receptor signaling mediates atherosclerosis associated with bacterial exposure and/or a high-fat diet in a murine apolipoprotein E heterozygote model: pharmacotherapeutic implications. Circulation 2004;110:1678-1685.

10 Oslund LJP, Hedrick CC, Olvera T, Hagenbaugh A, Territo M, Berliner JA, Fyfe AI: Interleukin-10 blocks atherosclerotic events in vitro and in vivo. Arterioscler Thromb Vasc Biol 1999;19:2847-2853.

-11 Robertson AKL, Rudling M, Zhou X, Gorelik L, Flavell RA, Hansson GK: Disruption of TGF- $\beta$ signaling in T cells accelerates atherosclerosis. J Clin Invest 2003;112:13421350.

12 Kawai T, Akira S: Pathogen recognition with Toll-like receptors. Curr Opin Immunol 2005; 17:338-344.

13 Beg AA: Endogenous ligands of Toll-like receptors: implications for regulating inflammatory and immune responses. Trends Immunol 2002;23:509-512.

14 Brikos C, O’Neill LA: Signalling of Toll-like receptors. Handb Exp Pharmacol 2008;183: 21-50.
15 Dunzendorfer S, Lee HK, Tobias PS: Flowdependent regulation of endothelial Tolllike receptor 2 expression through inhibition of SP1 activity. Circ Res 2004;95:684-691.

16 Erridge C, Burdess A, Jackson AJ, Murray C, Riggio M, Lappin D, Milligan S, Spickett CM, Webb DJ: Vascular cell responsiveness to Toll-like receptor ligands in carotid atheroma. Eur J Clin Invest 2008;38:713-720.

17 Yang X, Murthy V, Schultz K, Tatro JB, Fitzgerald KA, Beasley D: Toll-like receptor 3 signaling evokes a proinflammatory and proliferative phenotype in human vascular smooth muscle cells. Am J Physiol Heart Circ Physiol 2006;291:H2334-H2343.

18 Erridge C, Spickett CM, Webb DJ: Non-enterobacterial endotoxins stimulate human coronary artery but not venous endothelial cell activation via Toll-like receptor 2. Cardiovasc Res 2007;73:181-189.

19 Bjorkbacka H, Kunjathoor VV, Moore KJ, Koehn S, Ordija CM, Lee MA, Means T, Halmen K, Luster AD, Golenbock DT, Freeman MW: Reduced atherosclerosis in MyD88null mice links elevated serum cholesterol levels to activation of innate immunity signalling pathways. Nature Med 2004;10:416421.

20 Michelson KS, Wong MH, Shah PK, Zhang W, Yano J, Doherty TM, Akira S, Rajavashisth TB, Arditi M: Lack of Toll-like receptor 4 or myeloid differentiation factor 88 reduces atherosclerosis and alters plaque phenotype in mice deficient in apolipoprotein E. Proc Natl Acad Sci USA 2004;101: 10679-10684. 
21 Mullick AE, Tobias PS, Curtiss LK: Modulation of atherosclerosis in mice by Toll-like receptor 2. J Clin Invest 2005;115:31493156.

22 Liu X, Ukai T, Yumoto H, Davey M, Goswami S, Gibson FC III, Genco CA: Toll-like receptor 2 plays a critical role in the progression of atherosclerosis that is independent of dietary lipids. Atherosclerosis 2007;196: 146-154.

23 Madan M, Amar S: Toll-like receptor-2 mediates diet and/or pathogen associated atherosclerosis: proteomic findings. PLoS ONE 2008;3:e3204

-24 Lehr HA, Sagban TA, Ihling C, Zahringer U, Hungerer KD, Blumrich M, Reifenberg K, Bhakdi S: Immunopathogenesis of atherosclerosis: endotoxin accelerates atherosclerosis in rabbits on hypercholesterolemic diet. Circulation 2001;104:914-920.

-25 Ostos MA, Recalde D, Zakin MM, Scott-Algara $\mathrm{D}$ : Implication of natural killer $\mathrm{T}$ cells in atherosclerosis development during a LPS-induced chronic inflammation. FEBS Lett 2002;519:23-29.

-26 Edfeldt K, Swedenborg J, Hansson GK, Yan Z: Expression of Toll-like receptors in human atherosclerotic lesions: a possible pathway for plaque activation. Circulation 2002; 105:1158-1160.

-27 Niessner A, Shin MS, Pryshchep O, Goronzy JJ, Chaikof EL, Weyand CM: Synergistic proinflammatory effects of the antiviral cytokine interferon-alpha and Toll-like receptor 4 ligands in the atherosclerotic plaque. Circulation 2007;116:2043-2052.

28 Steinberg D, Witztum JL: Is the oxidative modification hypothesis relevant to human atherosclerosis?: Do the antioxidant trials conducted to date refute the hypothesis? Circulation 2002;105:2107-2111.

-29 Moore KJ, Kunjathoor VV, Koehn SL, Manning JJ, Tseng AA, Silver JM, McKee M, Freeman MW: Loss of receptor-mediated lipid uptake via scavenger receptor A or CD36 pathways does not ameliorate atherosclerosis in hyperlipidemic mice. J Clin Invest 2005; 115:2192-2201.

- 30 Funk JL, Feingold KR, Moser AH, Grunfeld C: Lipopolysaccharide stimulation of RAW 264.7 macrophages induces lipid accumulation and foam cell formation. Atherosclerosis 1993;98:67-82.

-31 Kalayoglu MV, Byrne GI: Induction of macrophage foam cell formation by Chlamydia pneumoniae. J Infect Dis 1998;177:725-729.

-32 Qi M, Miyakawa H, Kuramitsu HK: Porphyromonas gingivalis induces murine macrophage foam cell formation. Microb Pathog 2003;35:259-267.

-33 Kalayoglu MV, Byrne GI: A Chlamydia pneumoniae component that induces macrophage foam cell formation is chlamydial lipopolysaccharide. Infect Immun 1998;66:50675072.
34 Cao F, Castrillo A, Tontonoz P, Re F, Byrne GI: Chlamydia pneumoniae-induced macrophage foam cell formation is mediated by Toll-like receptor 2. Infect Immun 2007;75: 753-759.

35 Lee JG, Lim EJ, Park DW, Lee SH, Kim JR, Baek SH: A combination of Lox-1 and Nox 1 regulates TLR9-mediated foam cell formation. Cell Signal 2008;20:2266-2275. DOI 10.1016/j.cellsig.2008.08.022.

36 Castrillo A, Joseph SB, Vaidya SA, Haberland M, Fogelman AM, Cheng G, Tontonoz P: Crosstalk between LXR and Toll-like receptor signaling mediates bacterial and viral antagonism of cholesterol metabolism. Mol Cell 2003;12:805-816.

37 Baranova I, Vishnyakova T, Bocharov A, Chen Z, Remaley AT, Stonik J, Eggerman TL, Patterson AP: Lipopolysaccharide down regulates both scavenger receptor B1 and ATP binding cassette transporter A1 in RAW cells. Infect Immun 2003;70:2995-3003.

38 Blessing E, Kuo CC, Lin TM, Campbell LA, Bea F, Chesebro B, Rosenfeld ME: Foam cell formation inhibits growth of Chlamydia pneumoniae but does not attenuate Chlamydia pneumoniae-induced secretion of proinflammatory cytokines. Circulation 2002;105:1976-1982.

39 Tsan MF, Gao B: Review: pathogen-associated molecular pattern contamination as putative endogenous ligands of Toll-like receptors. J Endotoxin Res 2007;13:6-14.

40 Taylor KE, Giddings JC, van den Berg CW: C-reactive protein-induced in vitro endothelial cell activation is an artefact caused by azide and lipopolysaccharide. Arterioscler Thromb Vasc Biol 2005;25:1225-1230.

41 Bausinger H, Lipsker D, Ziylan U, Manié S, Briand JP, Cazenave JP, Muller S, Haeuw JF, Ravanat C, de la Salle H, Hanau D: Endotoxin-free heat-shock protein 70 fails to induce APC activation. Eur J Immunol 2002; 32:3708-3713

42 Tan MH, Sun Z, Opitz SL, Schmidt TE, Peters JH, George EL: Deletion of the alternatively spliced fibronectin EIIIA domain in mice reduces atherosclerosis. Blood 2004. 104:11-18

43 Kalinina N, Agrotis A, Antropova Y, DiVitto G, Kanellakis P, Kostolias G, Ilyinskaya O, Tararak E, Bobik A: Increased expression of the DNA-binding cytokine HMGB1 in human atherosclerotic lesions: role of activated macrophages and cytokines. Arterioscler Thromb Vasc Biol 2004;24:2320-2325.

44 Miller YI, Viriyakosol S, Binder CJ, Feramisco JR, Kirkland TN, Witztum JL: Minimally modified LDL binds to CD14, induces macrophage spreading via TLR4/MD-2 and inhibits phagocytosis of apoptotic cells. J Biol Chem 2003;278:1561-1568.
45 Walton KA, Hsieh X, Gharavi N, Wang S, Wang G, Yeh M, Cole AL, Berliner JA: Receptors involved in the oxidised 1-palmitoyl2-arachidonyl-sn-glycero-3-phosphorylcholine-mediated synthesis of interleukin-8: a role for Toll-like receptor 4 and a glycosylphosphatidylinositol-anchored protein. J Biol Chem 2003;278:29661-29668.

46 Erridge C, Webb DJ, Spickett CM: Toll-like receptor 4 signalling is neither sufficient nor required for oxidised phospholipid mediated induction of interleukin-8 expression. Atherosclerosis 2007;193:77-85.

$\checkmark 47$ Erridge C, Webb DJ, Spickett CM: 25hydroxycholesterol, 7 $\beta$-hydroxycholesterol and 7-ketocholesterol upregulate interleukin-8 expression independently of Toll-like receptor 1, 2, 4 or 6 signalling in human macrophages. Free Radical Res 2007;41:260266.

48 Bochkov VN, Kadl A, Huber J, Gruber F, Binder BR, Leitinger N: Protective role of phospholipid oxidation products in endotoxin induced tissue damage. Nature 2002; 419:77-81.

-49 Bluml S, Kirchberger S, Bochkov VN, Kronke G, Stuhlmeier K, Majdic O, Zlabinger GJ, Knapp W, Binder BR, Stockl J, Leitinger N: Oxidized phospholipids negatively regulate dendritic cell maturation induced by TLRs and CD40. J Immunol 2005; 175:501-508.

-50 Erridge C, Kennedy S, Spickett CM, Webb DJ: Oxidised phospholipid inhibition of Toll-like receptor (TLR) signalling is restricted to TLR2 and TLR4: roles for CD14, LPS-binding protein and MD2 as targets for specificity of inhibition. J Biol Chem 2008; 283:24748-24759.

51 Bochkov VN, Mechtcheriakova D, Lucerna M, Huber J, Malli R, Graier WF, Hofer E, Binder BR, Leitinger N: Oxidized phospholipids stimulate tissue factor expression in human endothelial cells via activation of ERK/EGR-1 and $\mathrm{Ca}(++) /$ NFAT. Blood 2002; 99:199-206.

52 Saikku P, Leinonen M, Tenkanen L, Linnanmaki E, Ekman MR, Manninen V, Manttari M, Frick MH, Huttunen JK: Chronic Chlamydia pneumoniae infection as a risk factor for coronary heart disease in the Helsinki Heart Study. Ann Intern Med 1992;116:273278.

53 Ridker PM, Hennekens CH, Stampfer MJ, Wang F: Prospective study of herpes simplex virus, cytomegalovirus, and the risk of future myocardial infarction and stroke. Circulation 1998;98:2796-2799.

54 Mayr M, Kiechl S, Willeit J, Wick G, Xu Q: Infections, immunity, and atherosclerosis: associations of antibodies to Chlamydia pneumoniae, Helicobacter pylori, and cytomegalovirus with immune reactions to heatshock protein 60 and carotid or femoral atherosclerosis. Circulation 2000;102:833-839. 
-55 Espinola-Klein C, Rupprecht HJ, Blankenberg S, Bickel C, Kopp H, Rippin G, Victor A, Hafner G, Schlumberger W, Meyer J; AtheroGene Investigators: Impact of infectious burden on extent and long-term prognosis of atherosclerosis. Circulation 2002;105:1521.

56 Moazed TC, Campbell LA, Rosenfeld ME, Grayston JT, Kuo CC: Chlamydia pneumoniae infection accelerates the progression of atherosclerosis in apolipoprotein E-deficient mice. J Infect Dis 1999;180:238-241.

57 Minick CR, Fabricant CG, Fabricant J, Litrenta MM: Atheroarteriosclerosis induced by infection with a herpesvirus. Am J Pathol 1979;96:673-706.

-58 Juvonen J, Juvonen T, Laurila A, Alakarppa $\mathrm{H}$, Lounatmaa K, Surcel HM, Leinonen M, Kairaluoma MI, Saikku P: Demonstration of Chlamydia pneumoniae in the walls of abdominal aortic aneurisms. J Vasc Surg 1997; 25:499-505.

59 Laman JD, Schoneveld AH, Moll FL, van Meurs M, Pasterkamp G: Significance of peptidoglycan, a proinflammatory bacterial antigen in atherosclerotic arteries and its association with vulnerable plaques. Am J Cardiol 2002;90:119-123.

-60 Lehtiniemi J, Karhunen PJ, Goebeler S, Nikkari S, Nikkari ST: Identification of different bacterial DNAs in human coronary arteries. Eur J Clin Invest 2005;35:13-16.

-61 Branger S, Casalta JP, Habib G, Collard F, Raoult D: Streptococcus pneumoniae endocarditis: persistence of DNA on heart valve material 7 years after infectious episode. J Clin Microbiol 2003;41:4435-4437.

-62 OttSJ, El Mokhtari NE, Musfeldt M, Hellmig S, Freitag S, Rehman A, Kuhbacher T, Nikolaus S, Namsolleck P, Blaut M, Hampe J, Sahly H, Reinecke A, Haake N, Gunther R, Kruger D, Lins M, Herrmann G, Folsch UR, Simon R, Schreiber S: Detection of diverse bacterial signatures in atherosclerotic lesions of patients with coronary heart disease. Circulation 2006;113:929-937.

63 Renko J, Lepp PW, Oksala N, Nikkari S, Nikkari ST: Bacterial signatures in atherosclerotic lesions represent human commensals and pathogens. Atherosclerosis 2008;201: 192-197.

-64 Meijer A, Roholl PJ, Gielis-Proper SK, Ossewaarde JM: Chlamydia pneumoniae antigens, rather than viable bacteria, persist in atherosclerotic lesions. J Clin Pathol 2000; 53:911-916.
65 Wright SD, Burton C, Hernandez M, Hassing $\mathrm{H}$, Montenegro J, Mundt S, Patel S, Card DJ, Hermanowski-Vosatka A, Bergstrom JD, Sparrow CP, Detmers PA, Chao YS: Infectious agents are not necessary for murine atherogenesis. J Exp Med 2000;191:14371442 .

66 Creely SJ, McTernan PG, Kusminski CM, Fisher M, Khanolkar M, Evans M, Harte AL, Kumar S: Lipopolysaccharide activates an innate immune system response in human adipose tissue in obesity and type 2 diabetes. Am J Physiol Endocrinol Metab 2007;292: E740-E747.

67 Wiedermann CI, Kiechl S, Dunzendorfer S, Schratzberger P, Egger G, Oberhollenzer F, Willeit J: Association of endotoxaemia with carotid atherosclerosis and cardiovascular disease: prospective results from the Bruneck Study. J Am Coll Cardiol 1999;34:19751981.

68 Pussinen PJ, Tuomisto K, Jousilahti P, Havulinna AS, Sundvall J, Salomaa V: Endotoxemia, immune response to periodontal pathogens, and systemic inflammation associate with incident cardiovascular disease events. Arterioscler Thromb Vasc Biol 2007; 27:1433-1439.

69 Szeto CC, Kwan BC, Chow KM, Lai KB, Chung KY, Leung CB, Li PK: Endotoxemia is related to systemic inflammation and atherosclerosis in peritoneal dialysis patients. Clin J Am Soc Nephrol 2008;3:431-436.

70 Erridge C, Attina T, Spickett CM, Webb DJ: A high-fat meal induces low-grade endotoxemia: evidence of a novel mechanism of postprandial inflammation. Am J Clin Nutr 2007;86:1286-1292.

71 Cani PD, Amar J, Iglesias MA, Poggi M, Knauf C, Bastelica D, Neyrinck AM, Fava F, Tuohy KM, Chabo C, Waget A, Delmée E, Cousin B, Sulpice T, Chamontin B, Ferrières J, Tanti JF, Gibson GR, Casteilla L, Delzenne NM, Alessi MC, Burcelin R: Metabolic endotoxemia initiates obesity and insulin resistance. Diabetes 2007;56:1761-1772.

72 Kim F, Pham M, Luttrell I, Bannerman DD, Tupper J, Thaler J, Hawn TR, Raines EW, Schwartz MW: Toll like receptor-4 mediates vascular inflammation and insulin resistance in diet-induced obesity. Circ Res 2007; 100:1589-1596.
73 Poggi M, Bastelica D, Gual P, Iglesias MA Gremeaux T, Knauf C, Peiretti F, Verdier M, Juhan-Vague I, Tanti JF, Burcelin R, Alessi MC: $\mathrm{C} 3 \mathrm{H} / \mathrm{HeJ}$ mice carrying a Toll-like receptor 4 mutation are protected against the development of insulin resistance in white adipose tissue in response to a high-fat diet. Diabetologia 2007;50:1267-1276.

74 Brun P, Castagliuolo I, Di Leo V, Buda A, Pinzani $M$, Palù G, Martines D: Increased intestinal permeability in obese mice: new evidences in the pathogenesis of nonalcoholic steatohepatitis. Am J Physiol Gastrointest Liver Physiol 2007;292:G518-G525.

75 Miller MA, McTernan PG, Harte AL, Silva NF, Strazzullo P, Alberti KG, Kumar S, Cappuccio FP: Ethnic and sex differences in circulating endotoxin levels: a novel marker of atherosclerotic and cardiovascular risk in a British multi-ethnic population. Atherosclerosis DOI: 10.1016/j.atherosclerosis.2008. 06.018 .

76 Rice JB, Stoll LL, Li WG, Denning GM, Weydert J, Charipar E, Richenbacher WE, Miller FJ, Weintraub NL: Low-level endotoxin induces potent inflammatory activation of human blood vessels: inhibition by statins. Arterioscler Thromb Vasc Biol 2003;23: 1576-1582.

77 Lynn M, Rossignol DP, Wheeler JL, Kao RJ, Perdomo CA, Noveck R, Vargas R, D’Angelo T, Gotzkowsky S, McMahon FG: Blocking of responses to endotoxin by E5564 in healthy volunteers with experimental endotoxaemia. J Infect Dis 2003;187:631-639.

78 O'Connor CM, Dunne MW, Pfeffer MA, Muhlestein JB, Yao L, Gupta S, Benner RJ, Fisher MR, Cook TD: Azithromycin for the secondary prevention of coronary heart disease events. The WIZARD study: a randomized controlled trial. JAMA 2003;290:14591466

79 Griffiths EA, Duffy LC, Schanbacher FL, Qiao H, Dryja D, Leavens A, Rossman J, Rich G, Dirienzo D, Ogra PL: In vivo effects of bifidobacteria and lactoferrin on gut endotoxin concentration and mucosal immunity in Balb/c mice. Dig Dis Sci 2004;49:579-589.

80 Rault-Nania M-H, Gueux E, Demougeot C, Demigne C, Rock E, Mazur A: Inulin attenuates atherosclerosis in apolipoprotein E-deficient mice. Br J Nutr 2006;96:840-844. 